\title{
CORRIGENDA
}

\section{Liprin- $\alpha 1$ regulates breast cancer cell invasion by affecting cell motility, invadopodia and extracellular matrix degradation}

\author{
V Astro, C Asperti, MG Cangi, C Doglioni and I de Curtis \\ Oncogene (2011) 30, 1850; doi:10.1038/onc.2011.56
}

Correction to: Oncogene (2011) 30, 1841-1849; doi:10.1038/

onc.2010.562; published online 13 December 2010

Since the publication of the above manuscript, the authors have identified an error in the author list; the name of the third author was presented incorrectly.

The corrected author list is shown above.

\section{Dissection of RAS downstream pathways in melanomagenesis: a role for Ral in transformation}

PJ Mishra, L Ha, J Rieker, EV Sviderskaya, DC Bennett, MD Oberst, K Kelly and G Merlino

Oncogene (2011) 30, 1850; doi:10.1038/onc.2011.65

Correction to: Oncogene (2010) 29, 2449-2456; doi:10.1038/

onc.2009.521; published online 1 February 2010

In this article the NRAS activation mutant used was

NRasG12V, not NRasQ61K, as reported previously. 